\title{
CONTENTS OF BIORHEOLOGY, VOLUME 25, NUMBER 6 TWENTYFIFTH ANNIVERSARY VOLUME
}

\section{VOLUMIE 25, NUMBER 6 25TH ANNIVERSARY VOLUME \\ MEMORIAL ISSUE FOR ROBIN FÅHRAEUS (1888-1968) \\ Contents}

\section{A.L. Copley}

P. Sourander and L.H. Breimer

A.L. Copley

R Holenstein and D.N. Ku

M.M. Kozlov, D. Lerche and W. Meier

T.S. Hakim and A.S. Macek

K. Takamizawa, K. Hayashi, T. Nakamura,

T. Kato and N. Tsushima

N. Rudraiah, D. Vortmeyer and B.H. Veena

\section{Editorial}

823 The 100th birthday of Robin Fåhraus Invited Contribution

827 Robin Fåhræus (1888-1968)

833 List of publications on hemorheology by Robin Fåhræus and tributes to him. A selection

Papers

835 Reverse flow in the major infrarenal vessels $-\mathrm{A}$ capacitive phenomenon

843 RBC membrane instability for large pipette deformation. A theoretical approach

857 Effect of hypoxia on erythrocyte deformability in different species

869 Change of hematocrit and blood viscosity in cholesterol-fed rabbits

879 Influence of electric field on the unsteady dispersion coefficient in couple-stress flow

891 Announcement

893 Abstracts of Eleventh Annual Meeting, Japanese Society of Biorheology, Kanazawa, Japan, 2-4 June, 1988

917 Contents of CLINICAL HEMORHEOLOGY, Volume 8 , Numbet 5

I Software Survey Section 